\title{
Effects of mastitis on ovarian function and fertility in dairy cows
}

\author{
David Wolfenson ${ }^{1 *}$, Zvi Roth1, Yaniv Lavon² and Gabriel Leitner ${ }^{3}$ \\ ${ }^{1}$ Department of Animal Sciences, Faculty of Agriculture, Food and Environment, the Hebrew \\ University, Rehovot 76100, Israel; ${ }^{2}$ Cattle Breeders Association, Caesarea 38900, Israel; ${ }^{3}$ Mastitis \\ Reference Center, the Veterinary Institute, Bet Dagan 50250, Israel
}

\begin{abstract}
Summary
Mastitis has a deleterious effect on reproductive responses and fertility of dairy cows, which depends on whether it occurs before or after artificial insemination (AI). Subclinical intramammary infection (IMI) before Al reduced steroid concentrations in the preovulatory follicle of approximately one third of lactating cows, and was associated with low expression of major steroidogenic genes. Consequently, IMI induced an attenuated LH surge and delayed ovulation in $30 \%$ of cows with subclinical IMI; the remaining $70 \%$ exhibited normal responses. The reason for the diversity in reproductive responses of individual cows to subclinical IMI is unclear. Mastitis induced by Gram-negative or Gram-positive bacteria disrupted the developmental competence of the pool of oocytes at the germinal vesicle stage, resulting in low blastocyst rates. The specific immune/inflammatory molecules involved in impairment of reproductive responses in subclinical mastitic cows are poorly documented. Exposure of small antral follicles to subclinical mastitis induced by Gram-positive bacterial toxins had a long-term effect by reducing estradiol concentrations of preovulatory follicles. Unlike chronic subclinical mastitis, the disruptive effect of short-term clinical IMI before Al is time-dependent and involves lowered conception when IMI occurs close to the time of insemination. The effect of clinical intramammary infection on corpus luteum function is equivocal. In a recent study, inter-estrus interval and progesterone concentration were unaltered in most (95\%) E. coli-mastitic cows treated with anti-inflammatory drugs. Fertility studies showed that fertility of subclinical mastitic cows is improved by the Ovsynch program, probably because of synchronized timing of ovulation relative to $\mathrm{Al}$ in cows that could otherwise exhibit delayed ovulation.
\end{abstract}

\section{Introduction}

Bovine mastitis or intra-mammary infection (IMI) is highly prevalent in dairy cattle, with about $20-40 \%$ of the lactating cows infected with bacteria, mainly in a subclinical form. Traditionally, mastitis is related to reduced milk production and quality, increased veterinary costs, risk of culling and occurrence of other diseases (Halasa et al. 2007). However, in the last decade, attention has been drawn to the disruptive effect of mastitis on reproduction and fertility.

Clinical mastitis is an acute short-term (on the order of days) event caused mainly by Gramnegative (G-) bacteria, in particular Escherichia coli. It is characterized by systemic and local signs of mammary gland inflammation and a sharp rise in somatic cell count (SCC) in the

Corresponding author E-mail: david.wolfenson@mail.huji.ac.il 
milk. The IMI triggers a complex acute-phase response that includes immune responses such as increased secretion of inflammatory proteins, cytokines, prostaglandins and other elements, which are detected in milk and serum (Shuster et al. 1991, Eckersall et al. 2001). Subclinical mastitis, caused mainly by Gram-positive $(\mathrm{G}+$ ) bacteria (Staphylococcus aureus, coagulase negative staphylococci and streptococci), is more common than clinical mastitis. It is a longterm chronic disease characterized by a moderate rise in SCC, with no apparent signs of local inflammation or systemic involvement. Infection may persist for several months or throughout lactation. Although long-term effects of subclinical mastitis decrease fertility, its negative impact on reproduction has been poorly documented and is discussed in detail herein.

The current review concentrates on the effect of clinical and subclinical, natural or induced mastitis on the reproduction of dairy cows, and describes ovarian responses and briefly discusses gonadotropin secretion and timing of ovulation. Immune or uterine responses to IMI and effects of lipopolysaccharide (LPS) or tumor necrosis factor alpha (TNF $\alpha$ ) on follicular thecal and granulosa cells are beyond the scope of this review, and are discussed elsewhere (Terranova 1997, Bornstein et al. 2004, Sakumoto \& Okuda 2004, Malinowski \& Gajewski 2010).

The review comprises five sections: (1) epidemiological studies of the effect of mastitis on fertility; (2) effects of naturally occurring and induced mastitis, mainly subclinical, on follicular functions. This major section of the review includes IMI effects on timing of ovulation, follicular steroids and growth dynamics; (3) effects of mastitis on oocyte quality and early embryonic development; (4) impact of IMI on luteal function; (5) approaches to improving fertility of subclinical mastitic cows.

\section{Mastitis and fertility}

Although mastitis has a negative impact on reproductive performance, epidemiological studies are controversial, in particular with regard to the timing of the disease (before or after Al), involvement of clinical or subclinical IMI, and whether the responsible isolates are $\mathrm{G}+$ or G- bacteria.

Clinical mastitis after Al is associated with low conception rate (CR) and more services per conception (Loeffler et al. 1999, Konig et al. 2006). Other studies show a negative effect of chronic SCC elevation (likely subclinical mastitis) after AI on conception (Konig et al. 2006, Pinedo et al. 2009). The effect of IMI before AI is controversial. A study by Klaas et al. (2004) claims that there is no effect on CR or days open. Others have reported that high SCC before Al has a minimal effect on the non-return rate (Miller et al. 2001). In contrast, Schrick et al. (2001) indicated that clinical and subclinical mastitis before AI increase days open and services per conception, irrespective of pathogen type. Supporting this, Santos et al. (2004) showed that CR is depressed by clinical mastitis caused by either G+ or G- bacteria occurring prior to AI. Reasons for the differences among studies could result from differences in cut-off values of SCC between healthy and infected cows, or timing of IMI relative to AI.

A recent study conducted in Israel based on 287,000 Als examined the association of probability of conception with SCC elevation around AI (Lavon et al. 2011a). Cured and newly infected subgroups (likely clinical IMI cows) had lower CRs than uninfected cows, but the chronic (likely subclinical IMI) subgroup showed the largest reduction in CR (Fig. 1) and the magnitude of the reduction was related to SCC elevation. A single high elevation of SCC represented a clinical event of mastitis and a lower probability of conception if it occurred 30 days after $\mathrm{Al}$ or 10 days prior to $\mathrm{Al}$, but not when it occurred more than 10 days before Al (Lavon et al. 2011a). The latter finding is supported by the physiological studies described 


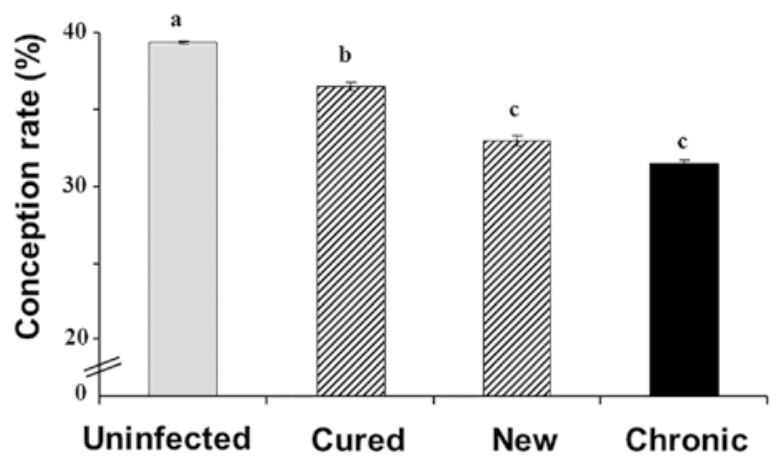

Fig. 1. Effect of mastitis type on first-Al conception rates (CRs) in lactating cows allocated to uninfected ( $n=178,512)$, cured ( $n=42,308)$, new infection $(n=19,998)$ or chronic infection ( $n=46,374$ ) groups. Data are presented as mean \pm SEM. Different letters denote significant differences at $P<0.05$.

further on. A similar negative effect on probability of conception due to clinical mastitic events was documented in the US by Hertl et al. (2010). In the UK, Hudson et al. (2012) showed that clinical and subclinical IMI occurring before or after $\mathrm{Al}$ reduce reproductive performance. Another study in the US showed that the negative impact on fertility is exacerbated when cows experience both clinical mastitis and other diseases (Ahmadzadeh et al. 2009).

\section{Follicular function}

Timing of ovulation

Clinical mastitis. A variety of stressors can disrupt the timing of ovulation and lower the probability of successful fertilization. Stress induction during specific stages of the cycle determines specific response impairments. Intrauterine or i.v. administration of an acute dose of LPS during the follicular phase suppressed primarily pulsatile LH secretion, which was further associated with delayed or blocked preovulatory LH surge and ovulation in sheep and cows (Peter et al. 1989, Battaglia et al. 2000, Suzuki et al., 2001, Daniel et al. 2003). Intramammary challenge with Streptococcus uberis during the luteal phase (Hockett et al. 2005) caused acute clinical mastitis that was associated with inhibition of ovulation. Several in vitro studies have shown that transiently elevated LPS or TNF $\alpha$ during the acute phase of clinical mastitic events decreases follicular estradiol production by granulosa cells (Spicer 1998, Sakumoto et al. 2003, Herath et al. 2007, Bromfield \& Sheldon 2011, Shimizu et al. 2012). Those studies indicated that acute mastitis occurring before estrus may directly suppress estradiol production, independent of any change in pulsatile $\mathrm{LH}$, resulting in inhibition of estrus and ovulation. Interestingly, intramammary or i.v. administration of an acute dose of LPS at the onset of estrus did not alter pulsatile LH or estradiol concentrations, but lowered and delayed LH surge and ovulation (Battaglia et al. 2000; Lavon et al. 2008). Similarly, sheep studies showed the importance of the exact time of exposure to LPS prior to LH surge in obtaining delayed ovulation syndrome (Breen et al. 2004). Collectively, the above studies indicate that an acute clinical event may effectively alter the timing of ovulation or block it entirely, provided that it is induced close to estrus and potential ovulation. These studies and several others only mimicked acute clinical events associated with induction of short-term acute-phase mastitis.

Whereas LPS is released into circulation and can be detected in the follicular fluid in postpartum uterine infection (Herath et al. 2007), this does not occur in clinical mastitis. A study 
by Mehrzad et al. (2007) showed that LPS is not detected in the plasma of most cows exhibiting acute clinical mastitis, with the exception of one cow that had severe clinical per-acute IMI. In agreement, another study only detected LPS in the circulation during mostly severe gangrenous mastitis (Hakogi et al. 1989). As most pathogenic bacteria causing subclinical IMI are G+, LPS is not likely to be detected in the circulation of subclinical mastitic cows. Therefore, the site of LPS administration is important; intramammary infusion of endotoxin more closely mimics clinical mastitis than i.v. or intrauterine administration or adding LPS to culture systems.

Subclinical mastitis. Although fertility studies have revealed that subclinical IMI is as harmful to reproduction as clinical IMI, supportive studies are rare and the involved inflammatory responses are unclear. A UK study showed a synergistic effect of lameness and high SCC ( $>100,000 \mathrm{cell} / \mathrm{mL}$ ) in reducing ovulation rate; however, cows with only a high SCC ovulated normally (Morris et al. 2009). In contrast, a study carried out in Israel (Lavon et al. 2010) showed that about $30 \%$ of subclinical mastitic cows (based on a SCC cutoff of $>200,000 \mathrm{cell} / \mathrm{mL}$ and bacterial diagnosis) manifested an extended estrus-to-ovulation interval of $56 \mathrm{~h}$ vs. $28 \mathrm{~h}$ in uninfected cows (Fig. 2). Estradiol concentration was lower in subclinical mastitic cows, likely leading to low, delayed or no preovulatory LH surge in the cows exhibiting delayed ovulation. The decline in estradiol was not associated with any change in pulsatile LH concentration, in contrast to acute events that were associated with depressed pulsatile LH secretion (Suzuki et al. 2001) and high circulating cortisol concentrations (Hockett et al. 2005). However, activation of the hypothalamic-pituitary-adrenal axis reflected by cortisol elevation during the acute phase (Lavon et al. 2008) was not evident in subclinical or past clinical mastitic cows (Lavon et al. 2010). Collectively, this shows that low estradiol in the circulation of $30 \%$ of subclinical IMI cows is due to one or more as yet unidentified inflammatory mediators capable of disrupting follicular steroidogenesis. Consequently, it is suggested that the stimulatory effect of estradiol on $\mathrm{GnRH}$ induction of LH surge secretion was probably depressed, leading to low, delayed or no LH surge and resulting in delayed ovulation (Lavon et al. 2010).

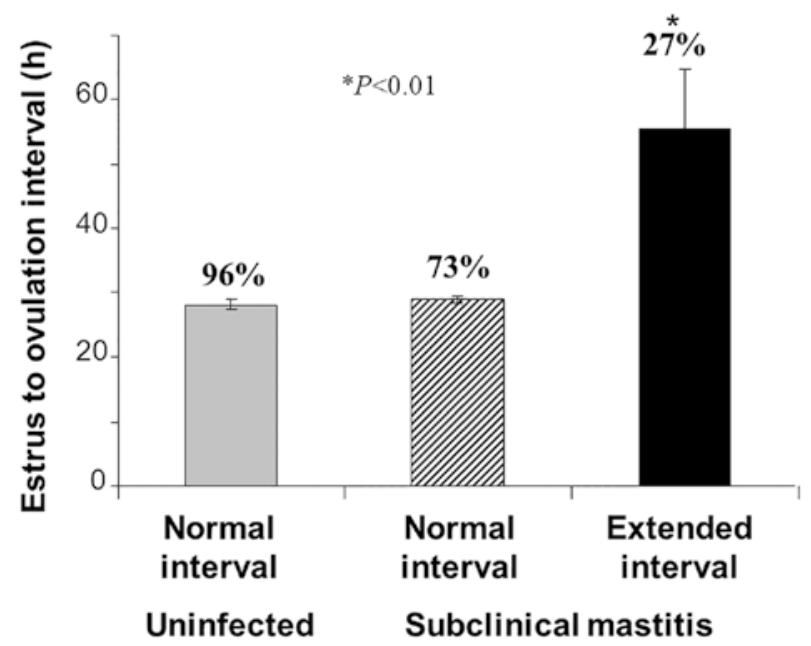

Fig. 2. Estrus-to-ovulation interval and percentage (\%) of cows exhibiting normal and extended interval.

\section{Follicular steroid production}

Naturally occurring subclinical mastitis. Only a few studies have examined the effects of subclinical mastitis on follicular responses. Lavon et al. (2011b) found a similar proportion 
of cows with delayed ovulation as in a previously described study (Lavon et al. 2010), with approximately one third of subclinical mastitic cows exhibiting low follicular fluid estradiol and androstenedione concentrations (Fig. 3B; 9/28 cows). These results corresponded with reduced expression of major genes associated with steroidogenesis: LHCGR in theca and granulosa cells, CYP11A1 and CYP17A1 in theca cells, and CYP19A1 in granulosa cells (Lavon et al. 2011b; Fig. 3A). Interestingly, expressions of STAR and HSD3B1 in theca cells and FSHR in granulosa cells were not affected by the subclinical mastitis (data not shown). However, the IMI events hardly affected follicular steroids when clinical mastitis occurred ca. 30 days prior to the study. The reason for the differential responses of the steroidogenic genes to IMI remains unclear.

(A)

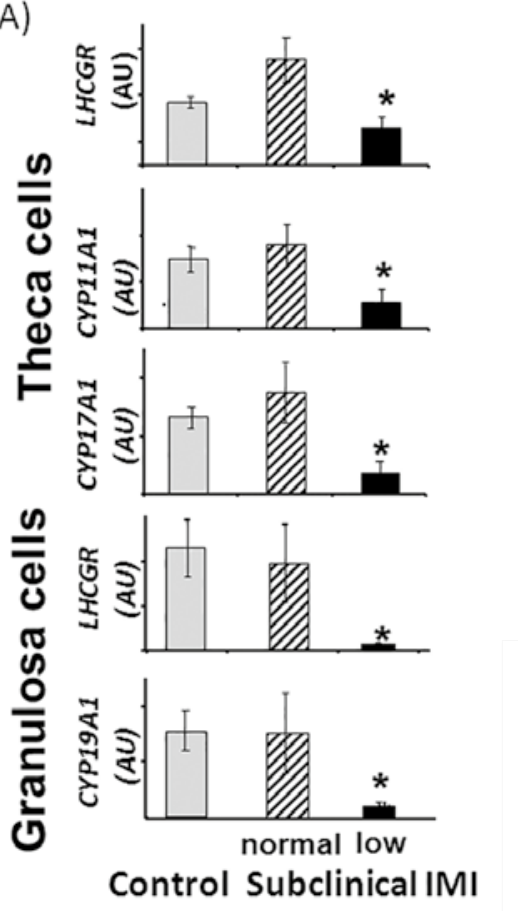

(B)

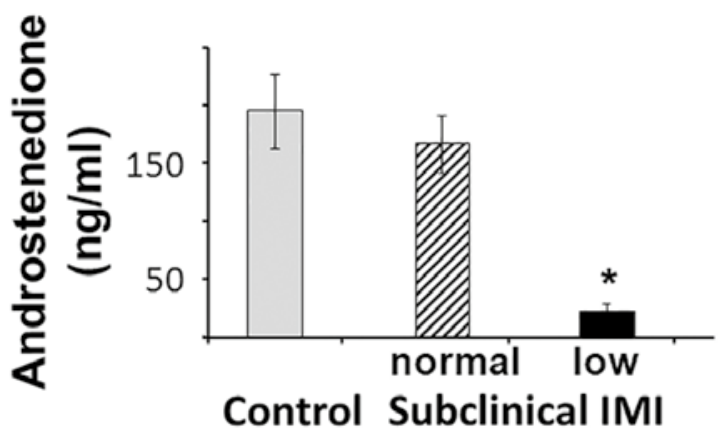

Fig. 3. (A) Expression of mRNA for gonadotropin receptor and steroidogenic genes in theca and granulosa cells collected from preovulatory follicles. RNA was extracted from uninfected and subclinical mastitic cows exhibiting normal or low estradiol in the follicular fluid. LHCGR, LH receptor; CYP19A1, cytochrome P450 aromatase; CYP11A1, cytochrome P450 side-chain cleavage; CYP17A1, cytochrome P450 17- $\alpha$-hydroxylase. (B) Concentrations of androstenedione in the follicular fluid of uninfected and subclinical mastitic cows exhibited normal or low estradiol concentrations in the follicular fluid.

Induced mastitis. The possible carryover effect of a clinical event on follicular responses (i.e., weeks after treatment) is of particular importance because clinical IMI before insemination lowers reproductive performance (Schrick et al. 2001, Santos et al. 2004, Pinedo et al. 2009). Intramammary administration of a single high dose of G- endotoxin (E. coli LPS) or G + toxin (of Staphylococcus aureus origin) enabled us to examine the immediate and carryover effects of mastitis. As expected, G- LPS caused an immediate and short-term decrease in follicular steroid concentrations (Lavon et al. 2011c), emphasizing that fertility disruption by a clinical event depends strictly on its timing relative to the occurrence of specific reproductive processes (e.g. ovulation, as discussed earlier). However, the $\mathrm{G}+$ toxin induced immediate and carryover (up 
to 3 weeks after injection) decreases in preovulatory follicular steroids. This indicates a long-term effect of mastitis on reproduction (discussed in more detail later further on).

A single intramammary injection of $E$. coli LPS appears to be an acceptable model for clinical mastitis. An experimental model was designed for induction of subclinical mastitis over a period of 3 weeks to more closely study subclinical mastitis induced by G+ or G- toxin (Furman et al. 2012). Intramammary injections of small doses of G- or G + toxin every $48 \mathrm{~h}$ for 20 days did not cause local signs of inflammation or systemic symptoms; body temperature, plasma cortisol and haptoglobin concentrations did not differ from those of non-treated controls. Similar to naturally occurring subclinical mastitis (Lavon et al. 2011b), diverse responses were recorded in a study in which cows had induced mastitis; about $40 \%$ of cows induced by $\mathrm{G}+$ and $80 \%$ of cows induced by G- were defined as 'affected' by the toxin. Both toxins caused a 40 to $50 \%$ carryover decrease (without any immediate reduction in follicular estradiol concentrations) 16 days after mastitis induction ended (Furman et al. 2012). It was clearly shown that small antral follicles of cows with induced subclinical mastitis for 3 weeks were affected and carryover damage was evidenced by lower estradiol concentrations in the preovulatory follicle. Another interesting finding was the similarity in follicular reduction of estradiol concentration induced by the two toxins, even though the innate immune system recognizes G+ and G- bacteria mainly through different toll-like receptors (TLR2 and TLR4, respectively) with different intracellular signaling pathways (Takeuchi et al. 1999).

Diversity in responses. The above studies of natural and induced mastitis present a large diversity in the follicular responses to the disease, with proportions of about 30:70 sensitive to non-sensitive subclinical mastitic cows (Lavon et al. 2010, 2011b, Furman et al. 2012). Interestingly, other studies have shown similar occurrences in cows and sheep. Exposure to various stressors, such as bacterial inoculation, LPS administration, cortisol-induced stress and sewage chemicals have shown differences among individual responses (Adams et al. 1999, Battaglia et al. 2000, Breen \& Karsch 2004, Hockett et al. 2005, Jacobsen et al. 2005, Bellingham et al. 2012). Variation also resides in the genetic differences among cows (Rupp \& Boichard 2003). This notion is supported by a study showing that mammary epithelial cells presenting the $\mathrm{Q}$ allele on autosome 18 have a stronger and quicker reaction to $E$. coli or $S$. aureus exposure than cells with the q allele (Brand et al. 2011).

\section{Follicular growth}

The effect of subclinical mastitis on follicular growth is equivocal. It seems to depend on the severity of the IMI. Chronic mastitis in severely affected cows decreased the number of secondary preantral follicles, as well as the number of follicles that were $>8 \mathrm{~mm}$ (Rahman et al. 2012). These findings were associated with a decreased density of blood vessels and decreased expression of growth differentiation factor 9 in the enclosed oocytes, known to be essential regulatory elements of follicular growth. These findings are in close agreement with our studies in which subclinical mastitis was induced by administering a single high dose of $G+$ toxin (Lavon et al. 2011c) or several small doses of $G+$ toxin over 3 weeks (Furman et al. 2012). Both toxin treatments caused a decrease in the number of medium-size follicles (6-9 mm, Fig. 4). Interestingly, naturally occurring subclinical mastitis caused an increase in the number of medium-size follicles that may be associated with depressed dominance (Lavon et al. 2010). The growth and size of the preovulatory follicle was not affected by either induced or naturally occurring mastitis (Lavon et al. 2010, 2011b, 2011c, Furman et al. 2012). It is worth noting that the latter finding is in contrast to the decline in size and growth of the dominant follicle recorded in cows exhibiting postpartum uterine disease (Sheldon et al. 2002). In summary, mastitis attenuates growth of 


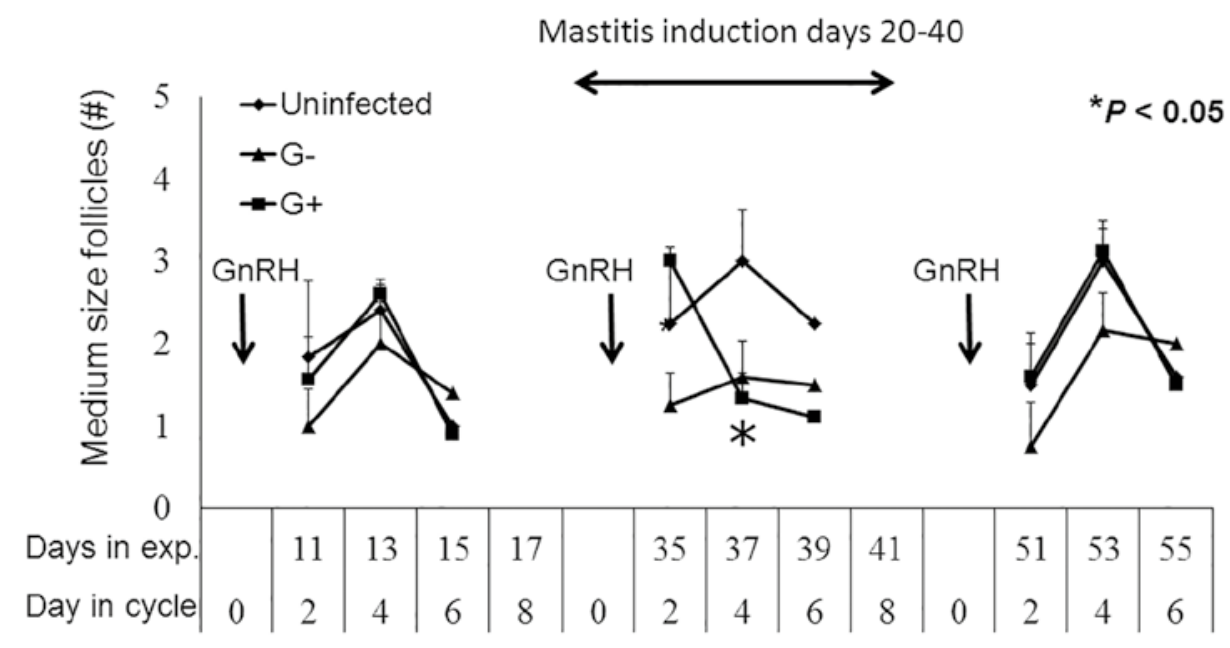

Fig. 4. Effect of subclinical mastitis induced by G- or G+ toxin over 3 weeks on number of medium-size follicles (6-9 mm) on days 2,4 and 6 of the induced cycle before, at the end of, and 16 days after the end of mastitis induction. IMI reduced the number of follicles at the end of exposure. Before exposure and 16 days later, all groups exhibited the typical rise on day 4 and decline on day 6 in the number of medium-size follicles, associated with dominance gained on day 5 .

preantral and medium-size follicles, but its association with reduced fertility of mastitic cows remains unclear.

\section{Oocyte competence}

Different approaches have been used to examine the effect of mastitis on oocyte competence. Initially, inflammatory agents (e.g. prostaglandin $\mathrm{F}_{2 \alpha^{\prime}} \mathrm{PGF}_{2 \alpha}$ ) added to the culture medium during oocyte maturation reduced the proportion of blastocysts formed, while addition of the nitricoxide generator sodium nitroprusside after fertilization prevented development to the blastocyst stage (Soto et al. 2003a). Additionally, TNF $\alpha$ added during maturation reduces the proportion of blastocysts formed, and when added after fertilization increases the percentage of blastomeres undergoing apoptosis (Soto et al. 2003b, Hansen et al. 2004). In mouse embryos, TNF $\alpha$ added during maturation decreased the number of cells in the inner cell mass, possibly associated with low embryonic survival (Pampfer et al. 1994, Wuu et al. 1999, Hansen et al. 2004).

Another approach that more closely mimics the effect of mastitis on oocyte competence is the use of follicular fluid from mastitic cows as oocyte maturation medium. Follicular fluid from G- or G + toxin-induced mastitic cows used as maturation medium reduced cleavage rate, and proportion of blastocysts formed was lower in the G- group and numerically lower in the $\mathrm{G}+$ group (Asaf et al. 2014). Although the inflammatory mediator(s) associated with reduced competence were not known, a main advantage of this study was the use of follicular fluids from mastitic cows containing inflammatory agents at physiological concentrations (Asaf et al. 2014).

Another method of examining the possible long-term effect of mastitis on oocyte competence involves oocyte collection for in vitro embryo production from mastitic cows. Oocytes were collected from culled Holstein cows that had been allotted to low-, medium- or high-SCC groups 
based on the SCC records for the last 3 months before slaughter (Roth et al. 2013). Although cleavage rate did not differ among the groups, blastocyst rate was markedly lower in mediumand high-SCC groups than in the low-SCC (control) group (Fig. 5). Interestingly, blastocyst rates did not differ among G- or G + bacterial types (Roth et al. 2013). This study provided evidence for disruption of the developmental competence of the ovarian pool of oocytes by naturally occurring mastitis at the germinal vesicle (GV) stage.

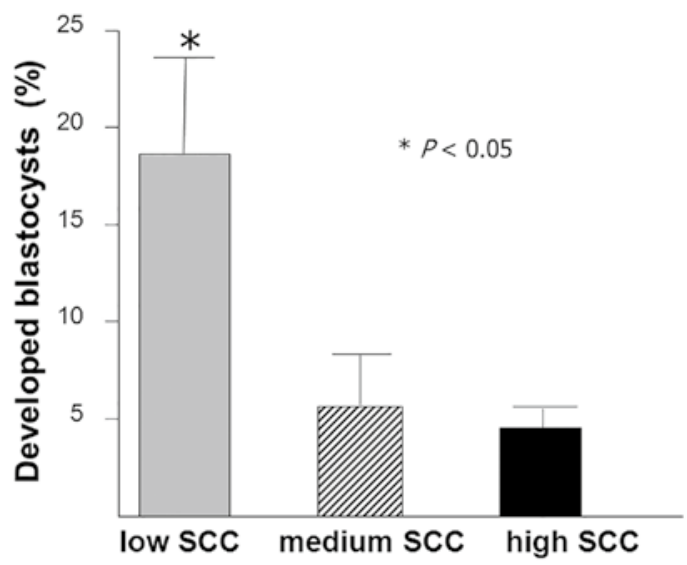

Fig. 5. Rate of blastocyst formation from oocytes aspirated from low- (controls), mediumand high-SCC groups recorded in culled cows for 3 months before collection of the ovaries at slaughter.

\section{Long-term disruptive effect of mastitis}

Several studies using different methodologies to explore long-term disruptive effects of mastitis on follicle function have revealed that small and less differentiated follicles are more susceptible to various inflammatory agents. Their early exposure to pathogenic stress may be expressed at a later stage as disrupted function in dominant follicles, resulting in low fertility. For instance, exposure of small antral follicles to intramammary administration of G + or G- toxin induced a carryover decrease in follicular estradiol in preovulatory follicles and a decrease in the number of medium-size follicles (Lavon et al. 2011c, Furman et al. 2012). Another study not directly related to IMI showed that bovine granulosa cells obtained from only small $(1-5 \mathrm{~mm})$ antral follicles have reduced estradiol production in response to cytokines added to the culture medium. No effect was detected with other categories of follicles (Spicer \& Alpizar 1994). It was also found in studies related to uterine infection that LPS inhibits the expression of TLR4, CD14, MD2 and NOD1 in granulosa cells from small ( $<5 \mathrm{~mm}$ in diameter) follicles (Shimizu et al. 2012) and reduces the number of bovine primordial follicles (Bromfield \& Sheldon 2013). Similar disruptive effects of naturally occurring mastitis on subordinate follicles have been documented. For instance, chronic mastitis reduced the number of secondary preantral and medium-size ( $>8 \mathrm{~mm}$ in diameter) follicles (Rahman et al. 2012). Another study showed that exposure of the pool of oocytes at the GV stage for 3 months before oocyte collection to various forms of mastitis causes a low rate of blastocyst formation (Roth et al. 2013). Taken together, these studies indicate a long-term disruptive effect of IMI and other pathogenic stresses on follicular function. 


\section{Corpus luteum}

A possible cause of low fertility in mastitic cows could be early regression of the corpus luteum $(\mathrm{CL})$ post-Al leading to pregnancy termination. Mastitis-induced increases in PGF $_{2 \alpha}$ and possibly TNF $\alpha$ have been related to CL regression in several studies (Sakumoto \& Okuda 2004, Malinowski \& Gajewski 2010). However, evidence for impaired luteal function in mastitic cows is controversial. Much of this is related to the various methodological approaches to stress induction by G- or G + toxin, the route of toxin administration (intramammary, i.v. or intrauterine) and assessment of the effects in clinical or subclinical mastitis.

\section{Induced stress}

Intravenous infusion of $E$. coli LPS for $6 \mathrm{~h}$ into pregnant cows decreased progesterone concentration over a period of $120 \mathrm{~h}$ (Giri et al. 1990). Another study showed that i.v. injection of LPS causes a decline in CL size and a transient decline in plasma progesterone concentration, associated with increased caspase-3 and decreased STAR expression (Herzog et al. 2012). Infusion of live E. coli into the uterus tended to shorten cycle length (Gilbert et al. 1990). In contrast, intramammary or i.v. administration of LPS at the onset of estrus did not affect cycle length or progesterone concentrations in most treated cows (Lavon et al. 2008). Effects of G+ bacteria and their toxins on luteal function are also controversial. Mammary inoculation with S. uberis did not alter progesterone concentration for 7 days post-administration (Hockett et al. 2005); however, i.v. administration of $\mathrm{G}+$ toxin (of Streptococcus origin) on day 5 after mating decreased progesterone concentrations for 16 to 19 days in sheep (Stewart et al. 2003, Dow et al. 2010). The above studies do not provide any conclusive evidence for the effect of induced stress on CL function.

\section{Naturally occurring mastitis}

Published outcomes from spontaneous cases of mastitis and their effect on CL lifespan have been unclear. Cows diagnosed as having mastitis with G-isolates were twice as likely to exhibit altered inter-estrus interval than healthy cows (Moore et al. 1991) and had a shorter luteal phase due to a higher rate of premature luteolysis (Huszenicza et al. 2005). In contrast, mid-luteal progesterone concentrations and CL volume in cows with past clinical events or subclinical mastitis did not differ from uninfected cows (Lavon et al. 2010). Another study showed that lameness combined with high SCC does not alter progesterone concentrations in cows (Morris et al. 2013). Similarly, progesterone profiles over 10 days following naturally occurring clinical mastitis (of E. coli origin) were not affected by IMI (Shaani et al. 2012). It is important to note that all mastitic cows in this study were given a commercial medication with a non-steroidal anti-inflammatory treatment at the time of diagnosis. This most likely attenuated or blocked prostaglandin release, resulting in $\mathrm{CL}$ maintenance. The same study showed that only a small portion of the cows $(5.5 \% ; \mathrm{n}=201)$ manifested estrus less than 8 days after $E$. coli mastitis, suggesting a negligible association between E. coli mastitis and short inter-estrus interval (Shaani et al. 2012). The above suggests that the cause of low fertility induced by $E$. coli mastitis after fertilization is directed at the embryo rather than the CL. 


\section{Approaches to improving fertility}

Among all of the reproductive functions disrupted by subclinical mastitis, the delayed ovulation found in one third of mastitic cows (Lavon et al. 2010) can be corrected. Two approaches were tested with the objective of improving fertility of subclinical mastitic cows; one was a management method and the other a hormonal treatment protocol.

The management approach to correcting the timing of $\mathrm{Al}$ in mastitic cows with delayed ovulation was based on the use of two inseminations: one was performed routinely after estrus, the second $24 \mathrm{~h}$ later (D Wolfenson 2010, unpublished observations). The findings of a study with 219 lactating cows showed that a single vs. two Als does not change CR of either healthy or subclinical mastitic cows. It is possible that the low LH surge seen in about $30 \%$ of the mastitic cows is involved in delayed ovulation and possibly altered oocyte maturation, preventing fertility improvement by double AI.

The Ovsynch protocol may improve timing of ovulation relative to that of estrus because the second $\mathrm{GnRH}$ injection induces an $\mathrm{LH}$ surge regardless of low steroidogenic capacity of the preovulatory follicle. In a recent study (D Wolfenson 2011, unpublished observations), 1,553 Holstein cows were subjected to either the Ovsynch 56 program (consisting of i.m. injection of GnRH followed 7 days later by $\mathrm{PGF}_{2 \alpha^{\prime}} 56 \mathrm{~h}$ later by a second injection of $\mathrm{GnRH}$ and $16 \mathrm{~h}$ later by timed $\mathrm{Al}$ ) or $\mathrm{Al}$ following natural estrus. A SCC threshold of 150,000 cell/mL milk was set for subclinical cows, and cows with postpartum uterine disease were recorded. Ovsynch significantly improved CR in subclinical mastitic cows relative to that in their control counterparts (Fig. 6). In contrast, Ovsynch did not improve CR in cows exhibiting postpartum uterine disease. Thus, the two major diseases affecting the dairy industry responded oppositely to the Ovsynch protocol, suggesting that different mechanisms underlie the disrupted fertility. A possible difference between the two diseases could be that subclinical mastitis induces delayed ovulation (Lavon et al. 2010), whereas postpartum uterine disease decreases the percentage of ovulating cows (Williams et al. 2008). This suggests that Ovsynch is capable of 'correcting' ovulation timing in mastitic but not endometritic cows.

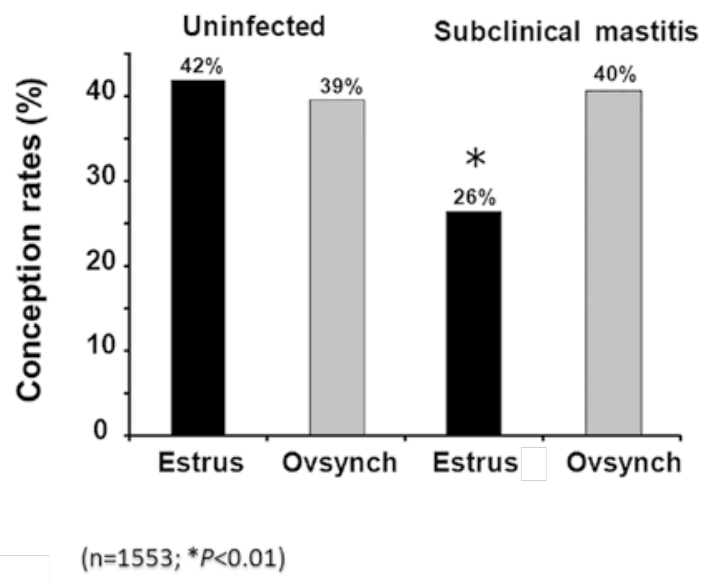

Fig. 6. Effect of Ovsynch 56 program on first-Al conception rate (CR) of subclinical mastitic and uninfected cows. Controls were artificially inseminated following natural estrus. 


\section{Conclusions}

1. Reduced fertility of subclinical mastitic cows before AI is associated with both follicleinduced delayed ovulation and impaired oocyte competence.

2. The potential of subclinical mastitis to disrupt follicular responses is higher than that of clinical mastitis, particularly before Al due to its long-term chronic nature.

3. Mastitis induces long-term disruption of ovarian follicular functions. A carryover effect (occurring weeks later) of subclinical mastitis induced by G+ or G- toxin is reflected in depressed follicular growth and low steroid production in the preovulatory follicle. Naturally occurring clinical or subclinical mastitis affects the pool of GV-stage oocytes and this is reflected after maturation in low blastocyst formation rates. The inflammatory agent(s) associated with subclinical mastitis that disrupts follicular functions is unknown.

4. There is large diversity in individual cows' reproductive responses to subclinical mastitis. The reason for the susceptibility of a particular subpopulation of cows to mastitic stress is unclear.

5. Several similarities are noted in the impairment of reproductive responses by $\mathrm{G}+$ and G- toxins despite their large differences in induction of immune responses and in their molecular/cellular pathways.

6. The effect of clinical IMI on possible disruption of CL function post-AI is equivocal; however, it seems to play a minor role in cows with clinical mastitis treated with anti-inflammatory drugs.

7. Conception rate of subclinical IMI cows can be improved by the Ovsynch-timed AI program, likely due to its synchronization of time of ovulation in cows that might otherwise exhibit delayed ovulation relative to Al.

\section{References}

Adams TE, Sakurai H \& Adams BM 1999 Effect of stresslike concentrations of cortisol on estradiol-dependent expression of gonadotropin-releasing hormone receptor in orchidectomized sheep. Biology of Reproduction 60 164-168.

Ahmadzadeh A, Frago F, Shafii B, Dalton JC, Price WJ \& McGuire MA 2009 Effect of clinical mastitis and other diseases on reproductive performance of Holstein cows. Animal Reproduction Science 112 273-282.

Asaf S, Leitner G, Furman O, Lavon Y, Kalo D, Wolfenson D \& Roth Z 2014 Effects of Escherichia coli- and Staphylococcus aureus-induced mastitis in lactating cows on oocyte developmental competence. Reproduction 147 33-43.

Battaglia DF, Krasa HB, Padmanabhan V, Viguie C \& Karsch FJ 2000 Endocrine alterations that underlie endotoxin-induced disruption of the follicular phase in ewes. Biology of Reproduction 62 45-53.

Bellingham M, McKinnell C, Fowler PA, Amezaga MR, Zhang Z, Rhind SM, Continot C, Mandon-Pepin B, Evans NP \& Sharpe RM 2012 Foetal and post-natal exposure of sheep to sewage sludge chemicals disrupts sperm production in adulthood in a subset of animals. International Journal of Andrology 35 317-329.
Bornstein SR, Rutkowski H \& Vrezas I 2004 Cytokines and steroidogensis. Molecular and Cellular Endocrinology 215 135-141.

Brand B, Hartmann A, Repsilber D, Griesbeck-Zilch B, Wellnitz O, Kuhn C, Ponsuksili S, Meyer HH \& Schwerin M 2011 Comparative expression profiling of E. coli and S. aureus inoculated primary mammary gland cells sampled from cows with different genetic predispositions for somatic cell score. Genetics, Selection, Evolution 43: 24.

Breen KM \& Karsch FJ 2004 Does cortisol inhibit pulsatile luteinizing hormone secretion at the hypothalamic or pituitary level? Endocrinology145 692-698.

Breen KM, Billings HJ, Debus N \& Karsch FJ 2004 Endotoxin inhibits the surge secretion of gonadotropin-releasing hormone via a prostaglandin-independent pathway. Endocrinology 145 221-227.

Bromfield JJ \& Sheldon IM 2011 Lipopolysaccharide initiates inflammation in bovine granulosa cells via the TLR4 pathway and perturbs oocyte meiotic progression in vitro. Endocrinology 152 5029-5040.

Bromfield JJ \& Sheldon IM 2013 Lipopolysaccharide reduces the primordial follicle pool in the bovine ovarian cortex ex vivo and in the murine ovary in vivo. Biology of Reproduction 8898 1-9. 
Daniel JA, Abrams MS, deSouza L, Wagner CG, Whitlock BK \& Sartin JL 2003 Endotoxin inhibition of luteinizing hormone in sheep. Domestic Animal Endocrinology 25 13-19.

Dow TL, Rogers-Nieman G, Holaskova I, Elsasser TH \& Dailey RA 2010 Tumor necrosis factor-alpha and acutephase proteins in early pregnant ewes after challenge with peptidoglycan-polysaccharide. Domestic Animal Endocrinology 39 147-154.

Eckersall PD, Young FJ, McComb C, Hogarth CJ, Safi S, Weber A, McDonald T, Nolan AM \& Fitzpatrick JL 2001 Acute phase proteins in serum and milk from dairy cows with clinical mastitis. Veterinary Record 148 35-41.

Furman O, Leitner G, Roth Z, Lavon Y, Jacoby S \& Wolfenson D 2012 Gram-negative or gram-positive toxin-induced subclinical mastitis affects preovulatory follicle responses in cows. Journal of Dairy Science 95, Suppl. 2 Abst. 666

Gilbert RO, Bosu WTK \& Peter AT 1990 The effect of Escherichia coli endotoxin on luteal function in Holstein heifers. Theriogenology 33 645-651.

Giri SN, Emau P, Cullor JS, Stabenfeldt GH, Bruss ML, Bondurant RH \& Osburn BI 1990 Effects of endotoxin infusion on circulating levels of eicosanoids, progesterone, cortisol, glucose and lactic acid, and abortion in pregnant cows. Veterinary Microbiology 21 211-231.

Hakogi E, Tamura H, Tanaka S, Kohata A, Shimada Y \& Tabuchi K 1989 Endotoxin levels in milk and plasma of mastitis-affected cows measured with a chromogenic limulus test. Veterinary Microbiology 20 267-274.

Halasa T, Huijps K, Osteras O \& Hogeveenb H 2007 Economic effects of bovine mastitis and mastitis management: A review. Veterinary Quarterly 29 18-31

Hansen PJ, Soto P \& Natzke RP 2004 Mastitis and fertility in cattle - possible involvement of inflammation or immune activation in embryonic mortality. American Journal of Reproductive Immunology 51 294-301.

Herath S, Williams EJ, Lilly ST, Gilbert RO, Dobson H, Bryant CE \& Sheldon IM 2007 Ovarian follicular cells have innate immune capabilities that modulate their endocrine function. Reproduction 134 683-693.

Herzog K, Strüve K, Kastelic JP, Piechotta M, Ulbrich SE, Pfarrer C, Shirasuna K, Shimizu T, Miyamoto A \& Bollwein H 2012 Escherichia coli lipopolysaccharide administration transiently suppresses luteal structure and function in diestrous cows. Reproduction 144 467-476.

Hertl JA, Grohn YT, Leach JD, Bar D, Bennett GJ, Gonzalez RN, Rauch BJ, Welcome FL, Tauer LW \& Schukken YH 2010 Effects of clinical mastitis caused by gram-positive and gram-negative bacteria and other organisms on the probability of conception in New York State Holstein dairy cows. Journal of Dairy Science 93 1551-1560.

Hockett ME, Almeida RA, Rohrbach NR, Oliver SP, Dowlen HH \& Schrick FN 2005 Effects of induced clinical mastitis during preovulation on endocrine and follicular function. Journal of Dairy Science $\mathbf{8 8}$ 2422-2231.

Hudson CD, Bradley AJ, Breen JE \& Green MJ 2012 Associations between udder health and reproductive performance in United Kingdom dairy cows. Journal of Dairy Science 95 3683-3897.
Huszenicza G, Janosi S, Kulcsar M, Korodi P, Reiczigel J, Katai L, Peters AR \& De Rensis F 2005. Effects of clinical mastitis on ovarian function in post-partum dairy cows. Reproduction in Domestic Animals 40 199-204.

Jacobsen S, Toelboell T \& Andersen PH 2005 Dose dependency and individual variability in selected clinical, haematological and blood biochemical responses after systemic lipopolysaccharide challenge in cattle. Veterinary Research 36 167-178.

Klaas IC, Wessels U, Rothfuss H, Tenhagen BA, Heuwieser W \& Schallenberger E 2004 Factors affecting reproductive performance in German Holstein-Friesian cows with a special focus on postpartum mastitis. Livestock Production Science 86 233-238.

Konig S, Hubner G, Sharifi R, Bohlsen E, Detterer J, Simianer H \& Holtz W 2006 Relation between the somatic cell count and the success of first insemination in East Frisian dairy herds on the basis of logistic models analysis. Zuchtungskunde 78 90-101.

Lavon Y, Leitner G, Goshen T, Braw-Tal R, Jacoby S \& Wolfenson D 2008 Exposure to endotoxin during estrus alters the timing of ovulation and hormonal concentrations in cows. Theriogenology 70 956-967.

Lavon Y, Leitner G, Voet H \& Wolfenson D 2010 Naturally occurring mastitis effects on timing of ovulation, steroid and gonadotrophic hormone concentrations, and follicular and luteal growth in cows. Journal of Dairy Science 93 911-921.

Lavon Y, Ezra E, Leitner G \& Wolfenson D 2011a Association of conception rate with the pattern and level of somatic cell count elevation relative to time of insemination in dairy cows. Journal of Dairy Science 94 4538-4545.

Lavon Y, Leitner G, Klipper E, Moallem U, Meidan R \& Wolfenson D 2011b Subclinical, chronic intramammary infection lowers steroid concentrations and gene expression in bovine preovulatory follicles. Domestic Animal Endocrinology 40 98-109.

Lavon Y, Leitner G, Moallem U, Klipper E, Voet H, Jacoby S, Glick G, Meidan R \& Wolfenson D 2011c Immediate and carryover effects of Gram-negative and Gram positive toxin-induced mastitis on follicular function in dairy cows. Theriogenology 76 942-953.

Loeffler SH, de Vries MJ \& Schukken YH 1999 The effects of time of disease ccurrence, milk yield, and body condition on fertility of dairy cows. Journal of Dairy Science $\mathbf{8 2}$ 2589-2604.

Malinowski E \& Gajewski Z 2010 Mastitis and fertility disorders in cows. Polish Journal of Veterinary Sciences 13 555-560.

Mehrzad J, Dosogne H, De Spiegeleer B, Duchateau L \& Burvenich C 2007 Bovine blood neutrophil acyloxyacyl hydrolase (AOAH) activity during endotoxin and coliform mastitis. Veterinary Research 5 655-668.

Miller RH, Clay JS \& Norman HD 2001 Relationship of somatic cell score with fertility measures. Journal of Dairy Science 84 2543-2548.

Moore DA, Cullor JS, Bondurant RH \& Sischo WM 1991 Preliminary field evidence for the association of clinical mastitis with altered interestrus intervals in dairy cattle. Theriogenology 36 257-265. 
Morris MJ, Walker SL, Jones DN, Routly JE, Smith RF \& Dobson H 2009 Influence of somatic cell count, body condition and lameness on follicular growth and ovulation in dairy cows. Theriogenology 71 801-806.

Morris MJ, Kaneko K, Uppal SK, S L Walker, Jones DN, Routly JE, Smith RF \& Dobson H 2013 Effects of high somatic cell counts in milk on reproductive hormones and oestrus behaviour in dairy cows with special reference to those with concurrent lameness. Animal Reproduction Science 141 20-5.

Pampfer S, Wuu YD, Vanderheyden I \& De Hertogh R 1994 Expression of tumor necrosis factor-a (TNF-a) receptors and selective effect of TNF-a on the inner cell mass in mouse blastocyst. Endocrinology 134 206-212.

Peter AT, Bosu WT \& DeDecker RJ 1989 Suppression of preovulatory luteinizing hormone surges in heifers after intrauterine infusions of Escherichia coli endotoxin. American Journal of Veterinary Research 50 368-373.

Pinedo PJ, Melendez P, Villagomez-Cortes JA \& Risco CA 2009 Effect of high somatic cell counts on reproductive performance of Chilean dairy cattle. Journal of Dairy Sciences 92 1575-1580.

Rahman MM, Mazzilli M, Pennarossa G, Brevini TA, Zecconi A \& Gandolfi F 2012 Chronic mastitis is associated with altered ovarian follicle development in dairy cattle. Journal of Dairy Science 95 1885-1893.

Roth Z, Dvir A, Kalo D, Lavon Y, Krifucks O, Wolfenson D \& Leitner G 2013 Naturally occurring mastitis disrupts developmental competence of bovine oocytes. Journal of Dairy Science 96 6499-6505.

Rupp R \& Boichard D 2003 Genetics of resistance to mastitis in dairy cattle. Veterinary Research 34 671-688.

Sakumoto R \& Okuda K 2004 Possible actions of tumor necrosis factor-alpha in ovarian function. Journal of Reproduction and Development $\mathbf{5 0} 39-46$.

Sakumoto R, Shibaya M \& Okuda K 2003 Tumor necrosis factor-alpha (TNF alpha) inhibits progesterone and estradiol-1 1 beta production from cultured granulosa cells: presence of TNFalpha receptors in bovine granulosa and theca cells. Journal of Reproduction and Development 49 441-449.

Santos JE, Cerri RL, Ballou MA, Higginbotham GE \& Kirk JH 2004 Effect of timing of first clinical mastitis occurrence on lactational and reproductive performance of Holstein dairy cows. Animal Reproduction Science 80 31-45.

Schrick FN, Hockett ME, Saxton AM, Lewis MJ, Dowlen HH \& Oliver SP 2001 Influence of subclinical mastitis during early lactation on reproductive parameters. Journal of Dairy Science 84 1407-1412.

Shaani Y, Leitner G, Shwimmer A, Day ML, Hogan JS, Furman O \& Wolfenson D 2012 Clinical mastitis is not associated with induction of luteal regression in dairy cows. Reproduction in Domestic Animals 47, Suppl. 4, Abst. 1001.

Sheldon IM, Noakes DE, Rycroft AN, Pfeiffer DU \& Dobson H 2002 Influence of uterine bacterial contamination after parturition on ovarian dominant follicle selection and follicle growth and function in cattle. Reproduction 123 837-845.

Shimizu T, Miyauchi K, Shirasuna K, Bollwein H, Magata F, Murayama C \& Miyamoto A 2012 Effects of lipopolysaccharide (LPS) and peptidoglycan (PGN) on estradiol production in bovine granulosa cells from small and large follicles. Toxicology In Vitro 26 1134-1142.

Shuster DE, Harmon RJ, Jackson JA \& Hemken RW 1991 Endotoxin mastitis in cows milked four times daily. Journal of Dairy Science $\mathbf{7 4}$ 1527-1538.

Spicer LJ 1998 Tumor necrosis factor-alpha (TNF-alpha) inhibits steroidogenesis of bovine ovarian granulosa and thecal cells in vitro: involvement of TNF-alpha receptors. Endocrine 8 109-115.

Spicer LJ \& Alpizar E 1994 Effects of cytokines on FSHinduced estradiol production by bovine granulosa cells in vitro: dependence on size of follicle. Domestic Animal Endocrinology 11 25-34

Soto P, Natzke RP \& Hansen PJ 2003a Identification of possible mediators of embryonic mortality caused by mastitis: actions of lipopolysaccharide, prostaglandin F2a, and the nitric oxide generator, sodium nitroprusside dihydrate, on oocyte maturation and embryonic development in cattle. American Journal of Reproductive Immunology 50 263-272.

Soto P, Natzke RP \& Hansen PJ 2003b Actions of tumor necrosis factor-a on oocyte maturation and embryonic development in cattle. American Journal of Reproductive Immunology 50 380-388.

Stewart AB, Inskeep EK, Townsend EC \& Dailey RA 2003 Effects of Gram-positive bacterial pathogens in ewes: peptidoglycan as a potential mediator of interruption of early pregnancy. Reproduction 125 295-299.

Suzuki, C, Yoshioka K, Iwamura S \& Hirose H 2001 Endotoxin induces delayed ovulation following endocrine aberration during the proestrous phase in Holstein heifers. Domestic Animal Endocrinology 20 267-278.

Takeuchi O, Hoshino K, Kawai T, Sanjo H, Takada H, Ogawa T, Takeda K \& Akira S 1999 Differential roles of TLR2 and TLR4 in recognition of gram-negative and gram-positive bacterial cell wall components. Immunity 11 443-451.

Terranova PF 1997 Potential roles of tumor necrosis factor-alpha in follicular development, ovulation, and the life span of the corpus luteum. Domestic Animal Endocrinology 14 1-15.

Williams EJ, Sibley K, Miller AN, Lane EA, Fishwick J, Nash DM, Herath S, England GC, Dobson H \& Sheldon IM 2008 The effect of Escherichia coli lipopolysaccharide and tumour necrosis factor alpha on ovarian function. American Journal of Reproductive Immunology $\mathbf{6 0}$ 462-473.

Wuu YD, Pampfer S, Becquet P, Vanderheyden I, Lee KH \& De Hertogh R 1999 Tumor necrosis factor a decreases the viability of mouse blastocyst in vitro and in vivo. Biology of Reproduction 60 479-483. 
